\title{
Culmen Infarct Triggers Isolated Body Backpulsion
}

\author{
Ken Ikeda, Yuji Kawase, Ryuta Sato, Yoshikazu Nakamura, Takehisa Hirayama \\ and Yasuo Iwasaki
}

Key words: truncal ataxia, rostal vermis infarct, culmen

(Inter Med 48: 1191, 2009)

(DOI: 10.2169/internalmedicine.48.2267)

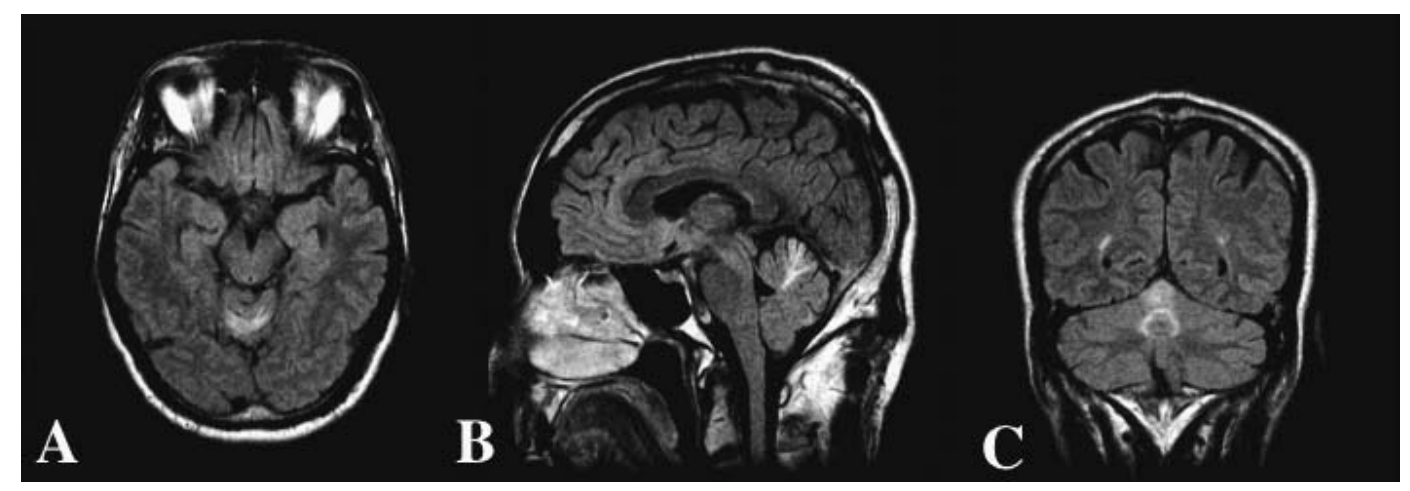

Picture 1. (A) Axial, (B) sagittal and (C) coronal sections of fluid-attenuated inversion imaging showing hyperintensity signal areas in the culmen of the rostral vermis.

A 62-year-old man with dyslipidemia who was a heavy smoker suddenly developed unsteadiness. Neurological examination showed an inability to sit and stand due to backward falling without other neurological signs. Brain MRI revealed selective lesions in the culmen of the rostal vermis (Picture 1A to 1C). Brain MR angiography and cerebral angiography disclosed no pathognomonic changes. He improved during the following 6 days.

Isolated truncal ataxia is rarely reported in patients with rostal vermis infarct $(1,2)$.
Anatomically speaking, the rostal vermis is divided into Larsell's lobules I (lingula) to VI (culmen) region. The rostal vermis controls posture and receives fibers from the dorsal spinocerebellar tract. The medial branch of the superior cerebellar artery supplies the rostal vermis (3). Previous causative lesions of truncal ataxia have been focused on Larsell's lobule II (centralis) $(1,2)$. The present unique case indicates that culmen infarct can elicit isolated body backpulsion.

\section{References}

1. Muley SA, Bushara KO. Isolated gait ataxia due to cerebellar vermis infarct. Arch Neurol 61: 1461, 2004.

2. Lee $\mathrm{H}$. Isolated body lateropulsion caused by a lesion of the rostal vermis. J Neurol Sci 249: 172-174, 2006.
3. Tatu L, Moulin T, Bogousslavsky J, Duvernoy H. Arterial territories of human brain: brainstem and cerebellum. Neurology 47: 1125-1135, 1996.

Department of Neurology, Toho University Omori Medical Center, Tokyo

Received for publication March 13, 2009; Accepted for publication March 23, 2009

Correspondence to Dr. Ken Ikeda, keni@med.toho-u.ac.jp

(C) 2009 The Japanese Society of Internal Medicine Journal Website: http://www.naika.or.jp/imindex.html 